\title{
The use of and alternatives for tropical hardwood in the Netherlands
}

\author{
Cor F. W. M. von Meijenfeldt
}

Forest and Wood Section, Rural Development Programme, Royal Tropical Institute, Mauritskade 63, 1092 AD Amsterdam, Netherlands

Key words: tropical hardwoods, wood utilization, rain forest conservation

\section{Summary}

In this paper, the imports and end-uses of tropical hardwood in the Netherlands are analysed. In recent years, imports were about 1 million $\mathrm{m}^{3} \mathrm{EQ}$ (roundwood equivalent) of solid tropical hardwood annually, of which $75 \%$ were used in the building industry. Windows and window frames are the main individual market outlets. For different end-uses, the most likely substitutes are shown. Softwood will be the principal substitute. The possibilities of using worked-up waste materials as an alternative are examined. Finally, some measures to counteract the negative ecological effects of using tropical hardwoods in the Netherlands are proposed.

\section{Introduction}

The tropical rain forests, the most diverse and complex ecosystems in the world, are seriously threatened at present. The most important threat is the conversion of the forests for agricultural purposes. Also, the exploitation of tropical hardwood is often seriously damaging the forests. Although these forests are often considered, 'common heritage of mankind', the depletion of the forests continues and will continue on an ever-increasing scale if nothing will be done to stop it.

The Dutch are using tropical hardwood too. In what way is the use of tropical hardwood in the Netherlands threatening the rain forests, how long can this use continue, and, if tropical hardwood will not be available any longer for whatever reason, what materials can be expected to act as substitutes? In order to answer these questions, the use of and alternatives for tropical hardwood in the Netherlands have been highlighted in a study initiated by the Foundation for the Conservation of Tropical Rain Forests. The Dutch Ministry of Housing, Physical Planning and Environment financed the study, and the work was implemented by the Royal Tropical Institute in Amsterdam. For all we know, this study is the first to relate the depletion of tropical rain forests to the use of tropical hardwood in an importing country. The results of the study are summarized in this paper. Furthermore, some measures to counteract the potential negative ecological effects of the use of tropical hardwood in the Netherlands are proposed. 


\section{Use of tropical hardwood in the Netherlands}

\section{History}

Before 1900 , the Netherlands only imported some special hardwoods from the tropics. Between the two world wars, the annual imports amounted to between 50000 and 100000 cubic metres roundwood equivalent ( $\left.\mathrm{m}^{3} \mathrm{EQ}\right)$. After World War II, and particularly after the early 1960 s, the imports rose enormously, reaching their maximum in 1979 , with imports of more than 1.5 million $\mathrm{m}^{3} \mathrm{EQ}$ (Table 1 ).

Over the years, the species composition of the imports changed as well. In the beginning only very special species, such as ebony, teak, mahogany and demerara greenheart, were imported. Later on they became too expensive and were partly replaced by less special species such as red meranti, merbau, azobé (ekki) and ramin. Nowadays, the old species have almost disappeared from import statistics.

This change in the species composition of the imports will be further explained by looking at the end-uses of the wood, as will be done further on in this paper.

The form in which tropical hardwood is imported has also undergone considerable changes over the years. Without taking into account the sheet materials (veneer and plywood), for which reliable import statistics are difficult to obtain and which have not been included in this study, the imports can roughly be divided into three categories of solid wood: roundwood (sawlogs and veneer logs), squared timber, and sawn wood. Over the years, the share in the imports of unprocessed roundwood has continued to decrease from $74 \%$ in 1939 to only $10 \%$ in 1984 (Table 1). In other words, the primary processing of tropical hardwood has almost disappeared from the Netherlands and has been translocated to the wood-producing countries.

The origin of the imports were and are more or less similar to those in world trade as far as tropical hardwood is concerned. Around $80 \%$ stems from South East

Table 1. Annual imports of solid tropical hardwood in the Netherlands, from $1939-1984$, in $1000 \mathrm{~m}^{3} \mathrm{EQ}^{1}$.

\begin{tabular}{llcr}
\hline Period & Logs and squared timber ${ }^{2}$ & Sawn wood & Total \\
1939 & 65 & 20 & 85 \\
1953 & 90 & 40 & 130 \\
1958 & 170 & 95 & 265 \\
$1960-62$ & 210 & 130 & 340 \\
$1963-65$ & 250 & 190 & 440 \\
$1966-68$ & 265 & 205 & 470 \\
$1969-71$ & 290 & 340 & 630 \\
$1972-74$ & 320 & 595 & 915 \\
$1975-77$ & 205 & 925 & 1130 \\
$1978-80$ & 175 & 1055 & 1230 \\
$1981-83$ & 170 & 1020 & 1190 \\
1984 & 135 & 1045 & 1180 \\
\hline
\end{tabular}

1 Factors of conversion: $1 \mathrm{~m}^{3}$ squared timber $=1.5 \mathrm{~m}^{3} \mathrm{EQ} ; 1 \mathrm{~m}^{3}$ sawn wood $=2.0 \mathrm{~m}^{3} \mathrm{EQ}$.

2 Imports of squared timber have been almost constant over the years, around $14000 \mathrm{~m}^{3} \mathrm{EQ}$ each year. 
Asia, $18 \%$ from Africa and $1.5 \%$ from South America.

The sharp increase in the imports is commonly explained by the following factors. A sharply increased supply of relative homogeneous and suitable timber on reliable conditions of delivery on the one hand, and, on the other hand, the development of a number of new end-uses for wood from the tropics.

In most cases tropical hardwood became a substitute for softwood, in some cases the wood was applied to new end-uses for wood in general or for expanding applications.

\section{Present situation}

The Netherlands are a small and densely populated country. Approximately 14 million people live and work on some $30000 \mathrm{~km}^{3}$ of land. Therefore, it is understandable that wood production in the country is low and a large amount of wood has to be imported annually. Without taking into account the pulp and paper sector, more than $90 \%$ of the needs for wood have to be imported. Of this, some $20 \%$, or 1.3 million $\mathbf{m}^{3} \mathrm{EQ}$ a year, originates from the tropics.

In 1983 , around $20 \%$ of the imports of tropical hardwood consisted of sheet materials. The remaining $80 \%$ of solid wood (logs, squared timber and sawn wood) were imported from about 30 countries. One of these countries, Malaysia, supplied $66 \%$ of the total. Five countries supplied $95 \%$ of the total. South East Asia supplied about $80 \%$ of the wood, Africa $19 \%$ (but $96 \%$ of the logs), and the remainder was supplied by South America.

In 1983, around 70 different wood species were imported. One species, red meranti, made up $53 \%$ of the imports; three species together some $77 \%$, six species some $86 \%$ and twelve species some $96 \%$.

All of these twelve species originate from the closed forests in the tropics, most of them from the (lowland) rain forests, some from forests on the transition to drier areas, and one species from the peat swamp forest. Hardly any wood stems from man-made forests, more than $99 \%$ being obtained by exploitation of natural forests.

Part of the imports of solid tropical hardwoods in the Netherlands are re-exported to neighbouring countries. Until the mid-1970s, this re-exported part of the imports has been around $8 \%$, but it has been growing ever since to about $25 \%$ in 1984. The growing importance of these re-exports can be explained by an increased installed kiln-drying capacity for sawn wood.

\section{Use of solid tropical hardwood}

\section{Introduction}

Without taking into consideration the changes in stocks, which are assumed to be constant over the years, the total use of solid tropical hardwood can be calculated by taking the imports minus the re-exports. This shows that the annual consumption has been around 1 million $\mathrm{m}^{3} \mathrm{EQ}$ over the past ten years. Over the past four years it was around $950000 \mathrm{~m}^{3} \mathrm{EQ}$ a year. 


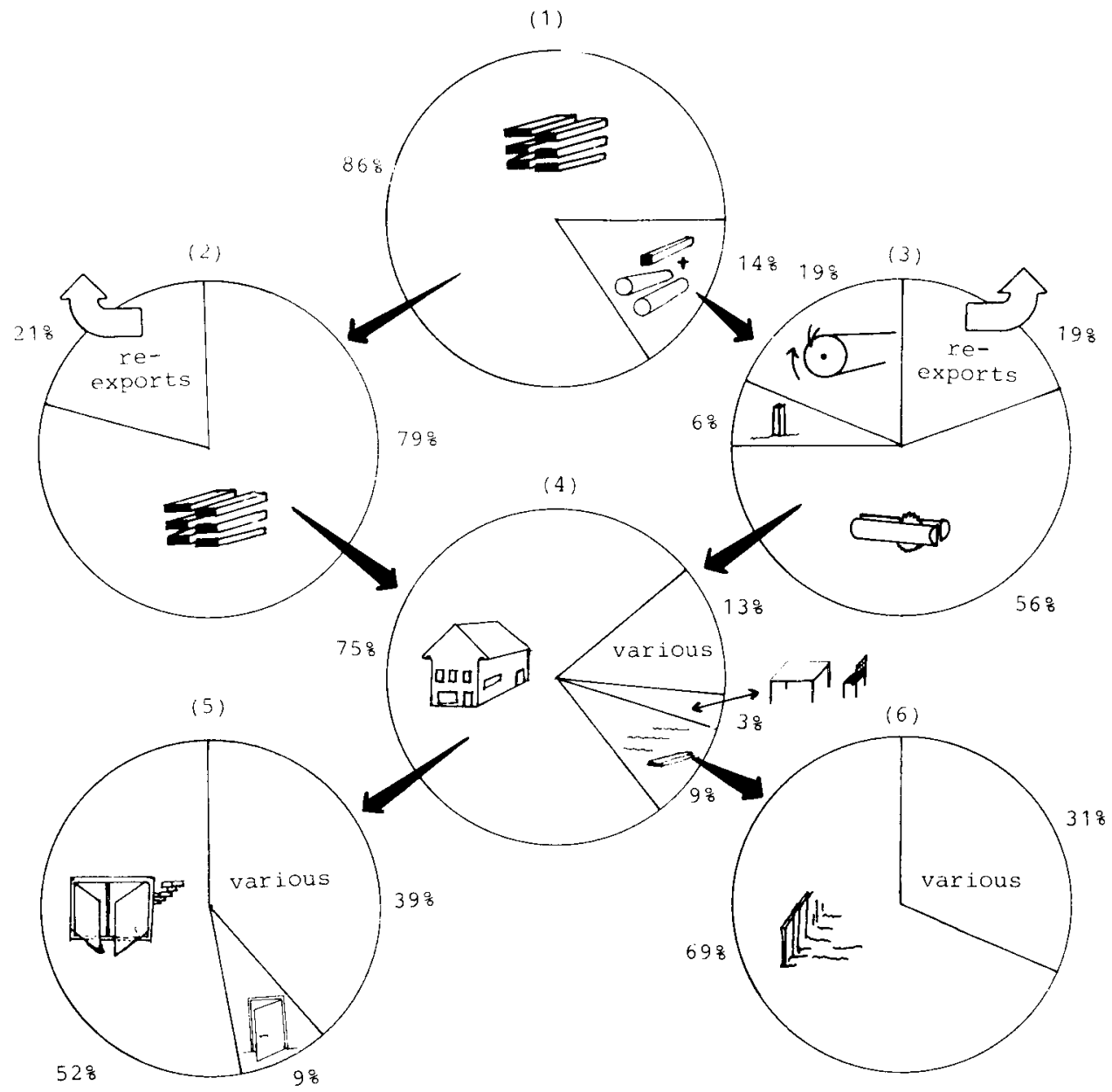

Fig. 1. Yearly flows of solid tropical hardwoods in the Netherlands, from imports to end-uses. Figures are annual means for the period 1981-1984. In $1000 \mathrm{~m}^{3} \mathrm{EQ}$.

(1) Imports of solid tropical hardwood $(100 \%=1190)$.

(2) Destination of sawnwood $(100 \%=1025)$.

(3) Destination of logs and squared timber $(100 \%=165)$.

(4) Use of sawnwood, by sectors of use $(100 \%=900)$.

(5) Use of sawnwood in building industry, by end-uses $(100 \%=675)$.

(6) Use of sawnwood in hydraulic engineering, by end-uses $(100 \%=80)$.

In Fig. 1, an estimate of the yearly flows of this solid wood, from imports until end-uses, is presented. The data represent annual means for the period 1981-1984. Of the imports, about $20 \%$ is re-exported, $1 \%$ is used as squared timber, $3 \%$ is peeled or sliced for veneer or plywood production and the remaining $76 \%$ is used as sawn wood. 
Of the sawn wood, about $75 \%$ has been used for the building industry, around $9 \%$ for hydraulic engineering, a few per cent for furniture and cabinet-making, and the remainder for other end-uses. About half of the sawn wood used in the building industry is applied for windows and window frames (about $350000 \mathrm{~m}^{3} \mathrm{EQ}$ annually). Outer doors (front as well as other outer doors) take $60000 \mathrm{~m}^{3} \mathrm{EQ}$ a year.

\section{Use of solid tropical hardwood in the building industry}

In the building industry, the main outlet for tropical hardwood are windows and window frames. Two-thirds of the wood used for these purposes is applied in the construction of new houses. In 1982, of all the windows in newly built houses, $70 \%$ were made of tropical hardwood. In 1971 this share was only $20 \%$, but it has increased ever since (Table 2), the share of windows made of softwood declining simultaneously. In other words, tropical hardwood became a substitute for softwood, and particularly for spruce.

Wood as such has kept its dominant position in the materials used for windows in house building. In Table 2, the choice of materials for windows is presented. In the renovation of houses and in the utility sector (offices, schools, factories, etc), other materials such as aluminium and plastics conquered a more or less important part of the market.

Already in 1971, the use of tropical hardwood for outer doors was considerable, especially for front doors, and it has increased ever since, particularly for other outer doors (kitchen doors, back doors, etc). In 1982, $58 \%$ of all outer doors of new houses were made of tropical hardwood. Other materials used for outer doors were softwood, non-tropical hardwood, plywood, metal and plastics.

Other applications for tropical hardwood in the building industry are stairs, balconies, base-boards, panelling, flooring, etc. It is not used for construction purposes, for which softwood is the only wood used.

The total amount of tropical hardwood used in the building industry depends on several important factors. Apart from the share of the material in the individual market outlets, which has risen markedly over the past twelve years, the following aspects are influencing total use.

- The number of houses and other buildings to be realized in a certain year. At the moment, the house-building programme is about 100000 units per year. In 1972

Table 2. Share (\%) of different materials for windows (including window frames) in new-built houses in the Netherlands, 1971-1982.

\begin{tabular}{lrrrrrr}
\hline Material & 1971 & 1974 & 1976 & 1978 & 1980 & 1982 \\
Softwood & 77 & 56 & 36 & 27 & 33 & 24 \\
Hardwood & 21 & 34 & 60 & 68 & 62 & 70 \\
Steel & 0 & - & - & & 0 & - \\
Aluminium & 2 & 10 & 4 & & 4 & 4 \\
Plastic & 0 & - & - & 5 & 0 & 2 \\
Others & 0 & 0 & - & & 0 & - \\
\hline
\end{tabular}


this number was still around 150000 units.

- The types of houses built, e.g. one-family houses versus flats. In the total, the share of one-family houses, which need more wood than flats, has decreased from $80 \%$ in 1976 to $64 \%$ in 1982.

- The way of financing the houses. In recent years most houses were built with government grants. The majority of these houses are smaller than purely privately financed houses. Per unit they have smaller windows and fewer outer doors.

If tropical hardwood has to be replaced, softwood will be undoubtedly the most important substitute. To a far lesser extent, substitutes will be non-tropical hardwood, plywood, aluminium, steel and plastics.

\section{Use of solid tropical hardwood in hydraulic engineering}

In the Netherlands, lying partly below sea-level, various water-works play an important role in maintaining the country as it is. Large ports, canals, sluices, dikes, etc., are all parts of the hydraulic infrastructure enabling the Dutch to live and work in coastal, originally swampy areas.

In this hydraulic infrastructure, tropical hardwood was traditionally used for special purposes only, such as poles (delphins) and sluice-doors. Only special species could be used, such as demerara greenheart and basralocus (angélique). Excellent mechanical properties, of which a high module of elasticity should be mentioned, very high durability and ample resistance to marine borers, as well as straight and long boles were, and still are requirements for these poles.

In hydraulic engineering, poles were traditionally the main market outlet for tropical hardwood, and every year some $10000 \mathrm{~m}^{3} \mathrm{EQ}$ are still used for this purpose. Yet other materials, such as steel and concrete, have taken over part of the market, although they are more expensive. This is due to the larger dimensions which are required in modern structures. The maximum dimensions of the boles limit the use of wood.

After World War II a new market for tropical hardwood was found in sheet-piling on banks of canals. These pile plankings, used for preventing the banks to erode as a result of the waves caused by passing ships, were traditionally hardly necessary and if used consisted mainly of softwood. At present, tropical hardwoods are used for this purpose. A rough estimate shows an annual use of about $55000 \mathrm{~m}^{3} \mathrm{EQ}$, mainly azobé (ekki). The cost of these walls made of azobé approximately equals that of walls made of preserved softwood. The latter is and will be the main substitute for tropical hardwood in this application. In general, other materials are either too expensive (e.g. steel) or do not perform as well (e.g. concrete).

\section{Alternatives for tropical hardwood}

As shown before, the most important alternative for the use of tropical hardwood in the Netherlands will be the use of softwood, whether preserved or not. The use of other materials, such as non-tropical hardwood, plywood, aluminium, steel, plastic and concrete, will be far less important.

A special group of alternatives which has been studied are recycled waste materi- 
als. Without going into detail, it can be stated that there are some possibilities to use worked-up waste materials as alternatives for tropical hardwood. First of all, wastes of tropical hardwood could be re-used. Lowering industrial waste will mean a more efficient use of the material. Old tropical hardwood could also be re-used, but at the moment the supply of old wood already used is still very low.

A second group of waste materials which could be useful are the wastes of other, non-tropical woods. Old, solid wood could be worked up and re-used, for instance for windows. Demolition of buildings is the main source of solid waste wood. A better organization of the demolition of buildings will be the most imporant prerequisite for attaining the re-use of solid waste wood.

Thirdly, working-up of waste plastics could yield products which can compete with tropical hardwood. On a small scale, this has already been done in the Netherlands. The products obtained are generally very durable but do not have very good strength properties. These products are used in industrial processes or for outside applications, for instance for roadside marks and poles of mail-boxes.

Two main questions arising if softwood were to replace tropical hardwood, are the availability and the economic, technical and environmental aspects of the preservation of softwood. Regarding the availability of softwood, three potential sources can be distinguished: the forests of North America and the USSR, still partly untapped, the forests of Europe, in which the annual growth is exceeding the annual fellings, and, thirdly, the forests of the Netherlands.

In Europe, the problems caused by the so-called acid deposition are affecting the productivity in the long run, in particular of the softwood forests. It seems reasonable to expect a sufficient availability of softwood in the short and medium run, whereas in the long run (more than 20 years) the availability will depend on special measures which should be taken in the near future, such as lowering the acidification of the air and expanding the forest area by new plantations. In this field some steps have already been taken by the Dutch government.

The second main point is the preservation of softwood in order to achieve a higher durability of the wood. In general, wood preservation is very advantageous from an economic point of view. In many cases, preserved softwood is less expensive than unpreserved tropical hardwood. Technically, some problems are still encountered when preserving wood, especially for the end-uses for which tropical hardwood is mostly used, such as windows and window frames. In what stage of manufacturing windows does preservation take place? How can this best be arranged in the joinery works? What method is best? In what way may voluntary or legal regulations be achieved to ensure a correct and effective preservation?

The environmental aspects of wood preservation concern above all the nature and effects of the agents used, as well as the effects on forests. The agents used for wood preservation are in general poisonous for man and his environment. In the process of preservation, the potential dangerous effects of the chemicals can be minimized without much difficulty. When using the preserved wood, leaching of the chemicals will be minimal if the wood is properly dried after preservation and the chemicals have had enough time to attach to the wood. Painting of the wood will further prevent leaching of the chemicals. 
After the termination of the use of preserved wood, the treatment of waste wood may cause problems for the environment. Waste wood not properly treated may cause air pollution or soil and water pollution. Controlled burning or re-use will be the best way to minimize the environmental dangers.

So far only the potential dangers of preservation have been mentioned. The principal environmental advantage of wood preservation is the economical use of the wood and therefore the preservation of the forests. If the disadvantages of wood preservation are minimized, it seems justified to state that the environmental advantages of wood preservation exceed the disadvantages.

\section{Effects of the use of tropical hardwood in the Netherlands on rain forests}

Of the exploited industrial tropical hardwood, about $35-40 \%$ is traded internationally. About $3.5 \%$ of the internationally traded tropical hardwood is used in the Netherlands. The five most important suppliers, covering together $95 \%$ of the Dutch needs, are Malaysia (including Singapore), Indonesia, Cameroun, Ivory Coast and Gabon. These five countries export $80 \%$ of their exploited industrial wood. The remaining $20 \%$ is used domestically. Almost all wood stems from natural forests, notably the rain forests.

Although it should be clear that exploitation of hardwood is generally not the main reason for degradation or conversion of the rain forests, it often has a negative impact (FAO, 1982). Wood production in a sustainable manner from the tropical rain forests is still very scarce. According to figures of FAO (1982), in the period 1981-1985 the area of closed forest under regular management would only increase by $40000 \mathrm{ha}\left(400 \mathrm{~km}^{2}\right)$ a year for the entire tropical zone.

Although new plantations could decrease the pressure on the rain forests, they will probably not be an alternative source for tropical hardwood. Species planted in monocultures are in general different from those exploited in the rain forests. The quality of the wood for the plantation-grown species is much poorer in general. Therefore, the wood will not be attractive to importing countries.

Three out of five most important countries supplying tropical hardwood to the Netherlands - Malaysia, Indonesia and Ivory Coast - together supplying $81 \%$ of the imports, are exploiting their forests so fast that in the medium run (10-15 years) the possibilities for continuation of the supply are very doubtful if nothing wili change in the management of their rain forests.

In considering the effects of the exploitation of tropical hardwood, one should bear in mind that in many cases merchantable wood makes the forest valuable and, therefore, will act as a kind of protection to the forest - not a protection of undisturbed forest but one of production forest. Production forests mean a choice of land-use with a lot of environmental and also economic benefits, the environmental benefits being always greater than those of non-forest land-use. Therefore, if tropical hardwood is not used, it will probably be disastrous to the rain forests in the long run. Other types of land-use will be chosen in that case, providing at least something, as can be seen with cattle-raising in the Amazon Basin and Central America: low meat production rates during a couple of years seem more profitable 
than forests not providing wood or other products.

One should also bear in mind that tropical hardwood is a very valuable source of income for certain countries. The net value of the imports in the Netherlands of tropical hardwood was about 600 million guilders in 1983 . The world trade in tropical hardwood in 1981 amounted to some $7 \times 10^{9}$ US dollars.

\section{Recommendations}

Before proposing suitable measures, the following considerations should be stated: - The depletion of the tropical rain forests continues, and at the moment it is obviously difficult to achieve a regular, sustainable management of the rain forests.

- New plantations are urgently needed in the tropics, but probably this does not imply an alternative source of tropical hardwood for the importing countries.

- The exports of wood are very important for the economies of the producing countries.

- The continuation of the possibilities to export in the medium run (10-15 years), as far as the three most important suppliers Malaysia, Indonesia and Ivory Coast are concerned, is very doubtful.

The following measures are proposed by which the Netherlands as a tropical hardwood importing country can contribute to the preservation of the tropical rain forest:

- The Netherlands and the European Economic Community should stimulate regular, sustainable management of the tropical rain forests. The import duties in the European Economic Community on processed wood from non-ACP countries could be a possible source of funds.

- The efficient use of tropical hardwood in the Netherlands should be stimulated through special measures.

- The use of certain types of waste as an alternative for tropical hardwood should be promoted.

- The use of softwood for windows and window frames and for pile planking could also be promoted, but further study on the availability of softwood and the various aspects of wood preservation is required.

- The measures mentioned above should also be promoted in other importing countries, and be discussed and taken in close cooperation with the producing countries. For this, the UNCTAD Agreement on Tropical Timber will be the right forum.

\section{References}

FAO, 1982. Tropical forest resources. FAO Forestry Paper No 30. FAO, Rome, Italy, $106 \mathrm{pp}$.

Meyenfeldt, C. F. W. M. von, 1985. (The use of and alternatives for tropical hardwoods in the Netherlands.) Ministry of Housing, Physical Planning and Environment, The Hague (Dutch). 